\title{
ПАТОГЕННЫЕ МИКОПЛАЗМЫ КРУПНОГО РОГАТОГО СКОТА Mycoplasma bovis, M. bovigenitalium И M. dispar: КРАТКАЯ ХАРАКТЕРИСТИКА ВОЗБУДИТЕЛЕЙ
}

\author{
(обзор)
}

\author{
М. АБЕД АЛХУССЕН 1 , В.В. КИРПИЧЕНКОㄹ, С.П. ЯЦЕНТЮК ${ }^{3}$, \\ А.А. НЕСТЕРОВ 2 , О.П. БЬЯДОВСКАЯ 2 , Т.В. ЖБАНОВА², А.В. СПРЫГИН ${ }^{2} ه$
}

Возбудители микоплазмоза крупного рогатого скота (КРС) широко распространены во всем мире, в том числе в Российской Федерации (А.М. Parker с соавт., 2018; М. Абед Алхуссен с соавт., 2020). В настоящем обзоре рассматриваются три патогенных микоплазмы КРС Mycoplasma bovis, M. bovigenitalium и M. dispar, их распространение, биологические свойства и лабораторные методы идентификации. Микоплазмы вызывают многочисленные заболевания КРС, включая маститы, артриты, кератоконъюктивиты, средний отит, пневмонии и репродуктивные патологии (R.A.J. Nicholas с соавт., 2008; F.P. Maunsell с соавт., 2011). Представители рода Mycoplasma характеризуются размером до 150 мкм, неболышим геномом (0,58-1,38 млн п.н.) с низким содержанием G-C (23-40 \%) и отсутствием клеточной стенки, что обусловливает их полиморфность и устойчивость к антибиотикам, влияющим на процесс синтеза клеточной стенки бактерий (R.A.J. Nicholas с соавт., 2008; P. Vos с соавт., 2011). Поверхностные антигены микоплазм отличаются высокой изменчивостью как in vitro, так и in vivo, благодаря чему наблюдается значительная вариабельность изолятов (М.A. Rasheed с соавт., 2017). Это также играет важную роль для преодоления иммунной системы организма-хозяина. Кроме того, некоторые из антигенов участвуют в адгезии микоплазм к клеткам-хозяевам (Y. Guo с соавт., 2017). После адгезии многие микоплазмы производят продукты, которые повреждают клетки хозяина и усиливают патогенез (L.A. Khan с coaвт., 2005). Они также могут образовывать биопленки, повышающие устойчивость к высыханию и тепловому стрессу (L. McAuliffe с соавт., 2006; F. Gomes с соавт., 2016). Более того, примембранное существование, внутриклеточная инвазия и выживаемость микоплазм в клетках КРС способствует сохранению этих патогенов и их распространению в организме хозяина (J. Van der Merwe c coавт., 2010). Инкубационный период при микоплазменной инфекции КРС зависит от инфекционной дозы, присутствия ассоциированных инфекций, условий содержания животных в стаде и стрессового состояния животных (М.J. Calcutt с соавт., 2018). Больные животные становятся источником инфекции, поскольку могут выделять патоген с носовыми истечениями и спермой в течение нескольких месяцев, а иногда и нескольких лет (К.A. Clothier с coaвт., 2010; V. Punyapornwithaya с соавт., 2010). При низких температурах микоплазмы длительное время сохраняют жизнеспособность вне организма хозяина. Так, в глубоко замороженной сперме КРС возбудитель может оставаться инфекционно-активным в течение многих лет (А. Kumar с coaвт., 2011). Высокая контагиозность некоторых видов Mycoplasma spp., сложности лечения микоплазмозов и экономические затраты на выбраковку пораженного поголовья обусловливают актуальность своевременной и точной диагностики для контроля и профилактики заболевания (A.M. Parker c coавт., 2018). Для выделения патогена, подтверждения его жизнеспособности и определения видовой принадлежности применяют культуральные методы исследования, однако у них много недостатков и ограничений. Культивирование микоплазм требует использования комплексных сред, специального оборудования и технических навыков (R.A.J. Nicholas c coaвT., 2008; M.J. Calcutt с соавт., 2018; A.M. Andersson с соавт., 2019). Его проводят при температуре $37^{\circ} \mathrm{C}$ и 5-10\% СО2 в течение 7-10 сут (P.J. Quinn с соавт., 2011). ПЦР-диагностика обеспечивает более быструю и точную идентификацию возбудителя, а с помощью серологических методов можно оценить иммунный ответ животных при вспышке микоплазмоза на ферме (A.M. Andersson с coaвт., 2019). Кроме того, для идентификации и изучения возбудителей микоплазмозов КРС используются другие методы, такие как метод масс-спектрометрии MALDI-TOF MS, метод полногеномного секвенирования (WGS), позволяющий изучать геном микроорганизмов, методы латексной агглютинации, иммунохроматографический анализ и др. Каждый из подходов имеет свои преимущества и недостатки (М.J. Calcutt с соавт., 2018; В. Pardon с соавт., 2020).

Ключевые слова: Mycoplasma bovis, Mycoplasma bovigenitalium, Mycoplasma dispar, крупный рогатый скот, характеристика возбудителей, эпизоотология, диагностика.

Представители рода Mycoplasma (класс Mollicutes) - это мелкие микроорганизмы, которые характеризуются отсутствием клеточной стенки, низким содержанием G-C (23-40 \%) и небольшим размером генома $(0,58-$ 1,38 млн п.н.) (1). Первый представитель рода Mycoplasma - Mycoplasma 
mycoides subsp. mycoides был выделен в 1898 году от больных коров и охарактеризован как возбудитель контагиозной плевропневмонии крупного рогатого скота (КРС) (2). Это опасное заболевание, достигнув глобального распространения в XIX веке, было успешно ликвидировано в большинстве стран мира, за исключением Африки, где оно до сих пор остается серьезной проблемой (3). К другим видам микоплазм, представляющим угрозу для КРС, относятся M. bovis, M. bovigenitalium, M. dispar, M. californicum, M. bovirhinis, M. bovoculi, M. leachii (ранеe Mycoplasma sp. bovine group 7) (4), M. canis, M. canadense, M. alkalescens, M. arginini и M. wenyonii (5-7).

Микоплазмы выступают как в роли секундарной микрофлоры, присоединяясь к патологическому процессу, вызванному другими микроорганизмами, так и в качестве первичных этиологических агентов в случае ослабления общей резистентности организма-хозяина. Микоплазмы вызывают многочисленные заболевания КРС, включая маститы, артриты, кератоконъюнктивиты, пневмонии и репродуктивные патологии (8). К наиболее распространенным патогенным и клинически значимым видам в настоящее время относят $M$. bovis, M. bovigenitalium и M. dispar.

В представленном обзоре рассматриваются три патогенных микоплазмы крупного рогатого скота - Mycoplasma bovis, M. bovigenitalium и M. dispar, их распространение, биологические свойства и лабораторные методы идентификации.

Клинические признаки микоплазменных инфекций, в ыз ванных $M$. bovis, M. bovigenitalium и M. dispar. Наиболее распространен среди КРС вид M. bovis, однако отмечались случаи его выделения от буйволов, мелких жвачных животных и кур (9). M. bovis становится основной причиной пневмонии молодняка КРС, однако и взрослый скот восприимчив к этому виду микоплазм (10). Смертность, обусловленная M. bovis, у телят составляет 5-10\%, заболеваемость - до $35 \%$ (6). Возбудитель не вызывает характерных клинических признаков: у животных отмечают резкий сухой кашель, лихорадку, апатию, выделения из глаз (6).

При развитии пневмонии M. bovis всегда выявляется в ассоциации с другими патогенными микроорганизмами. Поражения в легких могут отсутствовать или ограничиваться локализацией в апикальных долях в виде красноватых участков мультилобулярной консолидации (10). Однако при тяжелом течении инфекции могут наблюдаться обширные поражения легких с областью коагуляционного некроза и абсцессы (6). Хронические инфекции, вызванные $M$. bovis, характеризуются лимфоцитарной пневмонией, при которой отмечается гиперплазия перибронхиальной лимфоидной ткани, вызывающая стеноз просвета дыхательных путей, компрессию и коллапс прилегающей легочной паренхимы (11). Антиген M. bovis обнаруживается на периферии областей коагуляционного некроза, в некротических экссудатах и тесно связан с инфильтрирующими макрофагами и нейтрофилами (12). Пневмония может возникать как единственное проявление инфекции или в сочетании с другими клиническими признаками, включая полиартрит у взрослых животных и средний отит у молодых телят (13). M. bovis также способна вызывать субклинические, клинические или хронические маститы, что представляет серьезную проблему для производителей молока (14). M. bovis выявляли и при изучении абортированных плодов (14). Продолжением как респираторной, так и маститной формы течения заболевания могут быть артриты $(6,16)$, вызывающие нарушение двигательной функции, в тяжелых случаях - снижение потребления корма и истощение (6). Кроме того, M. bovis может приводить к эпидидимиту, орхиту, уретриту и семенному везикулиту быков (17). 
M. bovigenitalium была выделена из легких и репродуктивного тракта павших коров, а также от абортированных плодов КРС и буйволов, у которых наблюдали артрит и/или мастит (18). Известно, что M. bovigenitalium становится причиной развития некротического вульвовагинита, наносящего значительный ущерб племенному животноводству (19). Остро протекающие микоплазмозы приводят к серьезному повреждению вымени с поражением от одной до четырех долей (8). При проявлении мастита наблюдается уплотнение вымени и снижение удоя молока на фоне неэффективности антибиотикотерапии. В последние годы M. bovigenitalium часто выделяют из образцов влагалищных смывов и дыхательных путей КРС со сниженной фертильностью, эндометритами и/или зернистым вульвитом. Также M. bovigenitalium часто обнаруживается в образцах спермы, на слизистых оболочках половых органов в ассоциации с M. bovis (20).

M. dispar обнаруживается в дыхательных путях у клинически здоровых животных. Так, при исследовании поголовья КРС в Нидерландах M. dispar выявляли у $92 \%$ больных и $40 \%$ здоровых телят $(21,22)$. В Дании M. dispar выявляли в равной степени в образцах легких, отобранных от телят с признаками фибринозно-некротизирующей, гнойной бронхопневмонии и эмболической пневмонии (23). Исследования развития респираторных заболеваний у молочных телят показали возможную инициирующую роль M. dispar, приводящей к инвазии P. multocida (24).

M. dispar колонизирует эпителий слизистой оболочки дыхательных путей, оказывая цитостатическое и даже цитопатическое действие на клетки дистальных бронхов и бронхиол и приводя к уменьшенному трахеобронхиальному клиренсу (25). M. dispar вызывает образование уплотнений пурпурно-красного цвета, в основном в краниовентральных областях легкого (17). В Великобритании M. dispar часто выявляют у телят с признаками респираторной патологии. Считается, что возбудитель становится основной причиной тяжелой плевропневмонии и у взрослого поголовья КРС, иногда со смертельным исходом (26).

Э п и зо о тология. Впервые M. bovis была изолирована в США в 1961 году от КРС с тяжелой формой мастита (29). Возбудитель распространился во многие страны, включая Израиль (1964 год), Испанию (1967 год), Австралию (1970 год), Францию (1974 год), Великобританию (1974 год), Чехословакию (1975 год), Германию (1977 год), Данию (1981 год), Швейцарию (1983 год), Марокко (1988 год), Южную Корею (1989 год), Бразилию (1989 год), Северную Ирландию (1993 год), Ирландскую Республику (1994 год), Южную Африку (2005 год) (6).

M. bovis - наиболее значимый возбудитель микоплазмоза КРС. Его изучение было включено в финансируемый EC проект DISCONTOOLS (30). В Российской Федерации при исследовании 1186 проб биоматериала, полученных от КРС с клиническими признаками респираторной и/или репродуктивной патологии из 34 различных регионов в период с 2015 по 2018 год, геном M. bovis был обнаружен в 10,1\% проб, геном M. bovigenitalium выявлен в 8,6 \% проб, а геном $M$. dispar регистрировали в 37,15\% проб (31).

Сообщение о вспышке микоплазменного мастита, вызванного микоплазмой M. bovigenitalium, впервые было опубликовано в Англии в 1960 году (18). Многочисленные статьи подтверждают распространение этого вида микоплазм во всем мире. Также описаны единичные случаи выделения M. bovigenitalium из абортированного плода лошади и из семени хряка (32). M. bovigenitalium у КРС выявляли исследователи из Великобритании, США, Бразилии, Египта, Индии, Германии, Австрии, Хорватии, Дании, Нигерии, Италии, Японии, Турции, Нидерландов, Швейцарии, Южной Африки, 
Франции, Канады и Марокко $(6,33)$.

M. dispar - один из возбудителей, вызывающих респираторные заболевания KРС $(34,35)$. M. dispar впервые была выделена на территории Англии в 1969 году из пораженных легких телят (36). Затем M. dispar обнаружили в Дании, Бельгии, Голландии, Франции, Австралии, США, Канаде, Корее и Японии. В Европе сообщения о возбудителе поступали из Великобритании, (26). Инфекция, вызванная M. dispar, была зарегистрирована в Бразилии (37) и Италии (38).

Микробиологически е особенности. Идентификация и обнаружение микоплазм, поражающих КРС, проводится в первую очередь с помощью микробиологических методов. Из-за редуцированного генома микоплазмы не могут синтезировать ряд аминокислот и, в зависимости от вида, полностью или частично не способны синтезировать жирные кислоты. Эти нутриенты микоплазма получает из клетки хозяина.

Для выращивания микоплазм необходимо использовать питательные среды, содержащие бульон бычьего сердца, сыворотку, дрожжевой экстракт, пептон и другие добавки с буферизацией до конечного значения $\mathrm{pH}$ 7,3-7,8 (39). Примерами питательных сред для микоплазм служат питательная среда Эдвардса (на основе экстракта сердечной мышцы КРС и пептона с лошадиной сывороткой крови и дрожжевым экстрактом), среда УНИИЭВ (из триптического гидролизата), среда Мортона (на основе экстракта бычьего сердца и бактопептона), среда Хейфлика (модификация среды Мортона посредством добавления лошадиной сыворотки и дрожжевого экстракта).

Зачастую при выделении возбудителей микоплазмоза наблюдается зарастание питательных сред колониями других бактерий. Для решения этой проблемы в состав питательной среды включают антибактериальные препараты, к которым микоплазмы нечувствительны (5). Культивирование микоплазм проводят при $37{ }^{\circ} \mathrm{C}$ и 5-10\% $\mathrm{CO}_{2}$ в течение 7-10 сут. Сформированная колония имеет характерный для большинства микоплазм вид «яичницы» (рис.). Специфический вид колоний связан с тем, что их центральная часть врастает в агар, а на периферии находится зона поверхностного роста. Ряд микоплазм обладают своими характерными формами колоний, что позволяет дифференцировать их при культивировании (39).

A

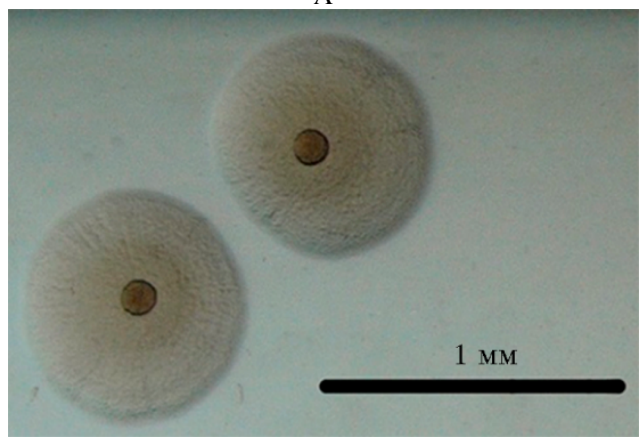

Б

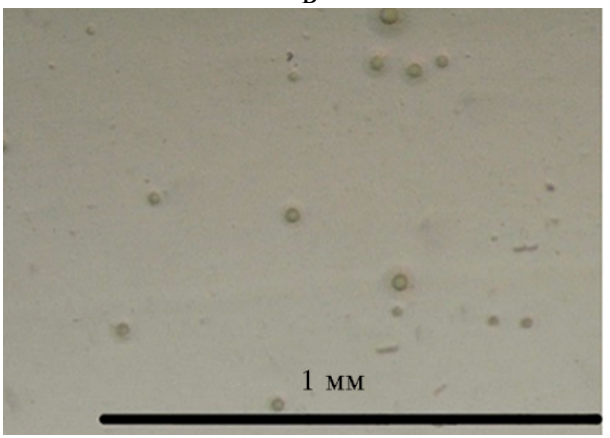

Колонии Mycoplasma bovis (3-суточная культура) (А) и M. bovigenitalium (5-суточная культура) (Б), культивируемые на твердой среде (https://www.mycoplasma-exp.com/speccultured.html).

M. bovis не ферментирует глюкозу и не гидролизует аргинин (40), вместо этого в качестве источников энергии возбудитель использует органические кислоты, такие как лактат и пируват. Один из продуктов метаболизма - пероксид водорода, фактор патогенности $(40,41)$. M. bovigenitalium не гидролизует аргинин и неферментированную глюкозу, но обладает фосфатазной активностью и восстанавливает соли тетразолия в анаэробных 
условиях (42). Возбудитель также способен вырабатывать пероксид водорода $(43,44)$. M. dispar не дает типичных колоний в виде «яичницы», особенно на ранних пассажах. Рост на питательных средах происходит медленно и требует 7-14 сут. M. dispar ферментирует глюкозу и восстанавливает соли тетразолия в аэробных и анаэробных условиях, но не гидролизует аргинин, не катаболизирует сыворотку и не обладает фосфатазной активностью $(6,22,44)$.

Устойчивостьк антимикробным препаратам. Микоплазмы не имеют клеточной стенки и устойчивы к антибиотикам, основной механизм действия которых заключается в подавлении процесса синтеза клеточной стенки бактерий. Микоплазмы также устойчивы к полимиксинам, сульфонамидам, триметоприму, налидиксовой кислоте и рифампицину (45-47). Антибиотиками, наиболее часто используемыми для контроля микоплазменных инфекций КРС, служат макролиды и тетрациклины. Линкозамиды, фторхинолоны, плевромутилины, фениколы и аминогликозиды также могут быть активны против микоплазм $(48,49)$. Большинство штаммов микоплазм остаются чувствительными к фторхинолонам, но наиболее эффективны плевромутилины (50).

У устойчивых к антибиотикам микоплазм были выявлены точечные мутации: в генах ДНК-гиразы и топоизомеразы IV - для фторхинолонов, в гене $23 \mathrm{~S}$ рРНК - для макролидов, линкозамидов, плевромутилинов и амфениколов, в гене $16 \mathrm{~S}$ рРНК - для тетрациклинов и аминогликозидов $(49,51,52)$.

Передача возбудителей. Основной механизм передачи аэрогенный путь. Микоплазмы попадают в организм при вдыхании контаминированных микрокапель и частиц пыли. При гематогенной передаче характерно поражение суставов.

Заражение телят происходит как посредством горизонтальной передачи через аэрозольную инфекцию дыхательных путей, так и в результате вертикальной передачи. Необходимо отметить, что для телят молоко также становится одним из основных источников инфекции, особенно в случае мастита (53). В исследованиях, проведенных с искусственно загрязненным материалом, сообщалось о достаточно длительном времени выживания микоплазм вне организма хозяина при низких температурах. Так, при $4{ }^{\circ} \mathrm{C}$ M. bovis остается активной в поролоне в течение 57 сут, в молоке - 54 сут, на соломе - 20 сут, на древесине и в воде -17 сут. Период выживания на этих материалах сокращался до $1-2$ нед при $20{ }^{\circ} \mathrm{C}$ и до 1 нед при $37{ }^{\circ} \mathrm{C}$ (54).

При 6-недельном исследовании молочного стада не обнаружено доказательств передачи возбудителя с загрязненным песком. Однако у 12 исследуемых телят микоплазмы были выявлены в пробах, отобранных из верхних дыхательных путей. Никаких признаков патологии при вскрытии при этом не наблюдали (55). В другой работе показано, что при клинической вспышке $M$. bovis песок из подстилки для животных без соответствующей обработки может представлять риск возникновения инфекций вымени (56).

Согласно проведенным в Дании исследованиям, основанным на четырех раундах скрининга молока, было установлено, что близкое расположение к фермам с подтвержденным микоплазмозом повышает риск заноса возбудителя в здоровое хозяйство. Также показан риск заноса инфекции при перемещении КРС между этими фермами $(57,58)$. Анализ случаев микоплазмозов среди близко расположенных хозяйств указывает на то, что при отсутствии или несоблюдении мер санитарного контроля происходит довольно быстрое распространение микоплазм между фермами (59). 
Контаминация спермы быков-производителей. M. bovis может оставаться инфекционно активной в течение многих лет в глубоко замороженной сперме КРС. Антимикробная обработка спермы малоэффективна (60).

Эксперименты in vitro показали, что при микроинъекциях M. bovis в эмбрионы активность возбудителя наблюдалась даже после тщательной промывки и обработки трипсином и комбинациями пенициллина, стрептомицина, линкомицина и спектиномицина или гентамицина, тилозина, линкомицина и спектиномицина (61). В России при исследовании методом ПЦР 410 образцов спермы из российских и зарубежных племенных центров ДНК M. bovis была обнаружена в 1,2 \%, M. bovigenitalium - в 43,4 \% образцов. В сперме также выявляли генетический материал M. californicum и Ureaplasma diversum. Нередки случаи инфицирования спермы сразу несколькими видами микоплазм (62). При исследовании 483 образцов спермы, полученных из 13 субъектов Российской Федерации в 2015-2018 годах, геном M. bovigenitalium был обнаружен в $29 \%$, M. bovis - в 11,6 \% образцов (31). Выделение микоплазм инфицированными животными в окружающую среду происходит не постоянно, поэтому единичные исследования по обнаружению патогена могут быть недостоверными (63).

Слизистая оболочка верхних дыхательных путей и молочные железы, по-видимому, представляют наиболее важное место персистирования и выделения M. bovis (64). Стрессовые события, такие как транспортировка, перегруппировка, перегон на откормочную площадку и стресс от холода, связаны с повышением агрессивности выделения M. bovis co слизистых оболочек (65). Хроническая бессимптомная инфекция с прерывистым выделением M. bovis имеет решающее значение для эпидемиологического процесса (8).

Ин кубац и о нны й п е р и д. Для микоплазменной инфекции инкубационный период во многом зависит от возраста и состояния животного. При экспериментальных инфекциях для маститной патологии он может составлять 2-4 сут, а для пневмонии - 7 сут. Имеются сообщения, что при вспышках мастита, вызванного микоплазмами, инкубационный период составлял 14 сут (66), в то время как в более ранней публикации (67) отмечалось, что инкубационный период при аналогичных вспышках составлял от 2 до 6 сут. Инкубационный период может также зависеть от инфекционной дозы, присутствия ассоциированных инфекций, условий содержания стада и стрессового состояния животных, особенно после транспортировки (68).

Особенности патогенеза и его молекулярные ме х а н и з м ы. Микоплазмы адгезируются на клетках хозяина для дальнейшего примембранного существования или последующей инвазии внутрь клеток. Адгезия - важный механизм вирулентности микоплазмы, что подтверждается изучением авирулентных штаммов, неспособных к прикреплению (69). У $M$. bovis было идентифицировано несколько адгезивных белков, в том числе белок Р26 с мембранной локализацией (70), плазминоген-связывающий фермент $\alpha$-енолаза (71), NADH-оксидаза (41) и несколько высокоизменчивых мембранных белков (VspA, VspB, VspE, VspF и VpmaX) (72, 73). Белки семейства Vsp самопроизвольно подвергаются рандомному фазовому изменению между состояниями «включения» и «выключения» экспресии. Высокая скорость самопроизвольного фенотипического переключения Vsp обусловлена частой перестройкой в соответствующих генах (68).

Такие генетические изменения влияют на вирулентность микоплазм, 
свойства биопленки (74), чувствительность к фагоцитозу и опосредованному комплементом лизису (75), а также молекулярному экранированию антигенов (76). Сравнительный геномный анализ разных изолятов M. bovis выявил множество антигенных вариаций поверхностных белков возбудителя. Идентификация и характеристика адгезинов способствует лучшему пониманию взаимодействия между M. bovis и клетками-хозяевами. Предполагается, что белки, связывающие фибронектин, и многофункциональный гликопротеин внеклеточного матрикса могут стимулировать бактериальную адгезию микоплазм к клеткам-хозяевам (77). У микоплазм выявлено несколько таких белков. Например, белок TrmFO M. bovis играет важную роль при связывании патогена с клетками, а также выполняет функцию тРНК метилтрансферазы (77). Еще одна отличительная особенность микоплазм - их способность проникать и размножаться в различных типах мононуклеарных клеток периферической крови КРС и в эритроцитах, что помогает защитить возбудителя от иммунной системы хозяина и противомикробных препаратов, а также способствует его быстрому распространению в организме зараженного животного (78). Антигены M. bovis были визуализированы в гепатоцитах и эпителиальных клетках (79), а инвазия, сопровождаемая внутриклеточной репликацией, продемонстрирована в эпителиальных клетках дыхательных путей эмбриона КРС (80).

Заслуживает внимания способность многих видов микоплазм образовывать биопленки (74). Несмотря на то, что формирование биопленок в основном продемонстрировано in vitro $(74,81,82)$, отдельные авторы сообщают, что они могут влиять на некоторые аспекты течения заболевания или патогенность микроорганизмов у $\mathrm{KPC}(83,84)$. При этом у микоплазм не обнаружены многие характерные для других видов бактерий гены, связанные со способностью образовывать биопленки.

У M. mycoides subsp. mycoides были идентифицированы ключевые белки, связанные с образованием биопленки, такие как фактор элонгации $\mathrm{Tu}$, глюкозо-специфический транспортер IIB системы PTS, фосфоенолпируватный белок фосфотрансфераза, фруктозо-бисфосфат-альдолазы II и пируватдегидрогеназа (85). При сравнении разных изолятов M. bovis была отмечена корреляция образования биопленки и соответствующего профиля экспрессии Vsp. Именно наличием биопленок может объясняться способность $M$. bovis выживать в подстилке $(56,86)$.

На сегодняшний день сообщается только об одном исследовании, в котором можно было соотнести конкретные гены M. bovis с его патогенностью. При сравнении 115-го, 150-го и 180-го пассажей изолята $M$. bovis со сниженной патогенностью с родительским изолятом дикого типа M. bovis НВ0801 идентифицировали 11 генов, влияющих на процесс аттенуации. Из них 10 связаны с метаболизмом и один кодирует вариабельный поверхностный белок (87). Однако in vivo ни для одного гена не доказано влияние на профиль вирулентности M. bovis (68).

Лабораторная ди агностика. Лабораторное подтверждение критически важно для постановки клинического диагноза, поскольку вызванные микоплазмами КРС клинические признаки не патогномоничны. Этиологию $M$. bovis часто не принимают во внимание до тех пор, пока не будут исключены другие патогенные микроорганизмы или пока животные не перестанут реагировать на антибиотикотерапию $(68,88)$. Для идентификации M. bovis и других видов микоплазм КРС в молоке, суставной жидкости, бронхоальвеолярном смыве, мазках из разных участков слизистой или образцах сыворотки применяют культуральные, молекулярные и серологические методы (89). Идентификация микоплазменных изолятов до вида 
крайне важна, поскольку такие виды, как M. bovigenitalium, M. bovis, M. dispar относятся к первичным патогенам, в то время как другие считаются частью резидентного микробиома, не играющего значительной роли в развитии заболевания (6).

Микробиологический метод традиционно считается стандартным для выявления микоплазм, но занимает много времени (18), требует использования обогащенной среды и антибиотиков (68). Существует также риск ложноположительных результатов из-за сходства колоний $M$. bovis с колониями других бактерий, принадлежащих к тому же классу. Также этот метод требует наличия жизнеспособных микроорганизмов (20). Чувствительность и специфичность микробиологического метода не определены для большинства бактерий, вовлеченных в развитие респираторных заболеваний КРС (88). Показано, что культивирование M. bovis на твердой среде, содержащей Tween 80, характеризуется 70,7 \% чувствительностью и 93,9 \% специфичностью (90).

Серологические методы используют для оценки эффективности вакцинации, определения иммунного статуса стада и динамики инфекции в более широком масштабе (91). Иммуноферментный анализ (ИФА) - инструмент только косвенного подтверждения инфекции, поскольку дает возможность обнаруживать антитела к M. bovis, но не присутствие самого возбудителя (20). ИФА рекомендуется использовать в сочетании с другими методами, что позволяет минимизировать ложноположительные результаты, связанные с наличием у здоровых животных антител к M. bovis $(20,88)$.

В течение последних двух десятилетий диагностика микоплазмозов проводится с использованием полимеразной цепной реакции (ПЦР) (88, 92). Однако ПЦР требует подбора специфичных олигонуклеотидных праймеров, при этом информация о нуклеотидной последовательности патогена должна быть получена заранее (88). Метод ПЦР, как правило, затратен, но для исследования можно использовать объединенные пробы и таким образом установить диагноз для группы животных (93-95).

В целом, молекулярные методы можно разделить на те, которые позволяют обнаруживать ДНК конкретного вида микоплазм (с использованием классической ПЦР или ПЦР в реальном времени) $(96,97)$, и методы, позволяющие обнаруживать микоплазмы без определения их видовой принадлежности. Для выявления микоплазм используют мультиплексную ПЦР $(98,99)$, ПЦР с гель-электрофорезом в денатурирующем градиенте, позволяющую дифференцировать виды микоплазм (100), ДНК-микрочипы и метод мультилокусного типирования $(38,101)$.

Используемый в последнее десятилетие метод масс-спектрометрии с матрично-активированной лазерной десорбцией/ионизацией (Matrix assisted laser desorption ionization time-of-light mass spectrometry, MALDI-TOF MS), который дает возможность идентифицировать бактерии по их уникальным белковым профилям, произвел своеобразную революцию в диагностике. Метод в основном используется для идентификации бактерий и микоплазм после культивирования $(91,102)$, однако он менее эффективен в полимикробных образцах и в образцах со смешанной инфекцией.

В последнее время для исследования бактериального генома широко применяют полногеномное секвенирование (next generation sequencing, NGS). Полученные данные используют для клинической диагностики, при исследовании вспышек заболеваний и при контроле устойчивости микроорганизмов к противомикробным препаратам (104). На сегодняшний день доступны полные последовательности генома для пяти изолятов M. bovis (105-107), двух изолятов M. californicum (108, 109), а также M. arginini (110), 
M. bovigenitalium (111), M. canadense (112), M. bovoculi (113) и M. leachii (114) (по одному изоляту).

Помимо описанных методов, в стадии разработки находятся методы латексной агглютинации и иммунохроматографический анализ (68). Кроме того, недавно был опубликован ряд работ, посвященных использованию петлевой изотермической амплификации для обнаружения M. bovis $(115,116)$.

Таким образом, Mycoplasma bovis, M. bovigenitalium и M. dispar наиболее важные представители класcа Mollicutes, поражающие крупный рогатый скот (КРC). Они вызывают множество заболеваний, наиболее значимые из которых маститы, пневмонии, репродуктивные расстройства и артриты у телят и взрослых животных. Эти заболевания могут носить хронический характер, снижая резистентность КРС к другим вирусным и бактериальным патогенам. Смертность может достигать $10 \%$, заболеваемость - 35 \%. Микоплазменные инфекции негативно влияют на экономическую производительность ферм. Проникновение возбудителя в стадо чаще всего происходит от зараженных животных с субклиническим течением болезни. Однако существует и множество других путей заноса микоплазм. Из-за хронической природы микоплазменных заболеваний и наличия субклинических форм выявление инфекции может быть затруднено. Резистентность микоплазм к большому числу противомикробных препаратов затрудняет антибиотикотерапию настолько, что для некоторых заболеваний, например мастита, в настоящее время рекомендуется убой всех пораженных животных. Сложности лечения микоплазмозов обусловливают актуальность профилактики этих заболеваний. К сожалению, разработка микоплазменной вакцины - сложная задача, и пока такие вакцины в качестве инструмента для контроля микоплазменных инфекций КРС рассматривать нельзя. В результате эпидемиологических исследований были выявлены определенные факторы риска распространения микоплазмозов, такие как ввод новых животных и несоблюдение гигиены доения. Профилактике заболевания способствует своевременная и точная диагностика. Тем не менее, чтобы полностью понять механизм распространения микоплазм, необходимы дополнительные исследования и разработка эффективных программ контроля микоплазмозов.

\footnotetext{
1ФГАОУ ВО Российский университет

дружбы народов,

117198 Россия, г. Москва, ул. Миклухо-Маклая, 6,

e-mail: alhussenmohammed85@hotmail.com;

2ФГБУ Федеральный иентр охраны здоровья животных,

600901 Россия, г. Владимир, мкр. Юрьевец, ФГБУ ВНИИзЖ,

e-mail: kirpichenko@arriah.ru,nesterov@arriah.ru,

bjadovskaya@arriah.ru,zhbanova@arriah.ru, sprygin@arriah.ru $\bowtie$;

ЗФГБУ Всероссийский государственный

Центр качества и стандартизации лекарственных

средств для жиивотных и кормов,

123022 Россия, г. Москва, Звенигородское ш., 5,

e-mail: pcr-lab@vgnki.ru
}

Поступила в редакцию

Sel'skokhozyaistvennaya biologiya [Agricultural Biology], 2021, V. 56, № 2, pp. 245-260

Mycoplasma bovis, M. bovigenitalium AND M. dispar

AS BOVINE PATHOGENS: BRIEF CHARACTERISTICS OF THE PATHOGENS

(review)

M. Abed Alhussen', V.V. Kirpichenko², S.P. Yatsentyuk ${ }^{3}$, A.A. Nesterov², 
IPeople's Friendship University of Russia (RUDN University), 6, ul. Miklukho-Maklaya, Moscow, 117198 Russia, e-mail alhussenmohammed85@hotmail.com;

${ }^{2}$ Federal Center for Animal Health Control, FGBU VNIIZZh, mkr. Yurievets, Vladimir, 600901 Russia, e-mail kirpichenko@arriah.ru, nesterov@arriah.ru,bjadovskaya@arriah.ru, zhbanova@arriah.ru, sprygin@arriah.ru( $₫$ corresponding author);

${ }^{3}$ Russian State Center for Animal Feed and Drug Standardization and Quality, 5, Zvenigorodskoe sh., Moscow, 123022 Russia, e-mail pcr-lab@vgnki.ru

ORCID:

Abed Alhussen M. orcid.org/0000-0002-1210-0303

Kirpichenko V.V. orcid.org/0000-0002-2494-3826

Yatsentyuk S.P. orcid.org/0000-0002-4819-2131

Nesterov A.A. orcid.org/0000-0002-4288-1964

The authors declare no conflict of interests

Received December 9, 2020

Byadovskaya O.P. orcid.org/0000-0002-8326-7151

Zhbanova T.V. orcid.org/0000-0002-9857-5915

Sprygin A.V. orcid.org/0000-0001-5982-3675

doi: 10.15389 /agrobiology.2021.2.245eng

\section{Abstract}

The cattle mycoplasmas are widespread throughout the world (A.M. Parker et al., 2018; M. Abed Alhussen et al., 2020). This review presents data on the epidemiology and diagnosis of mycoplasmosis in cattle caused by $M$. bovis, $M$. bovigenitalium, and $M$. dispar. Mycoplasmas can cause economically important diseases in cattle, including mastitis, arthritis, keratoconjunctivitis, otitis media, pneumonia, and reproductive disorders (R.A.J. Nicholas et al., 2008; F.P. Maunsell et al., 2011). Mycoplasmas are characterized by a size of up to $150 \mu \mathrm{m}$, small genome (0.58-1.38 million base pairs) a low G-C composition (23-40 \%) and the absence of a cell wall which determines their polymorphism and resistance to antibiotics, influencing the synthesis of the bacterial cell wall (R.A.J. Nicholas et al., 2008; P. Vos et al., 2011). Mycoplasma surface antigens are highly variable both in vitro and in vivo, which leads to significant variability of isolates (M.A. Rasheed et al., 2017). They also play an important role in overcoming the host's immune system. In addition, some of these antigens are involved in the adhesion of mycoplasmas to host cells (Y. Guo et al., 2017). After adhesion, many mycoplasmas produce a variety of products that damage host cells and enhance pathogenesis (L.A. Khan et al., 2005). They can also form biofilms that increase resistance to drying out and heat stress (L. McAuliffe et al., 2006; F. Gomes et al., 2016). Moreover, the invasion and intracellular survival of mycoplasmas in cattle cells contributes to the preservation and spread in the host organism ( $\mathrm{J}$. Van der Merwe et al., 2010). The incubation period for mycoplasma infection in cattle depends on many factors, i.e., the infectious dose, the presence of associated infections, the conditions of keeping the animals in the herd and the stress state of the animals (M.J. Calcutt et al., 2018). Sick animals are a source of infection, because they can shed the pathogen with nasal discharge and sperm for several months and sometimes for several years (K.A. Clothier et al., 2010; V. Punyapornwithaya et al., 2010). It should be noted that at low temperatures, mycoplasmas remain viable for a long time: in deeply frozen cattle semen, the pathogen can remain infectious for many years (A. Kumar et al., 2011). The high contagiousness of some species of Mycoplasma spp., their low sensitivity to treatment and the associated consequences of culling for the affected population make timely and accurate diagnosis important for disease control and prevention (A.M. Parker et al., 2018). The cultural methods can be applied for isolation and identification of the pathogen. However, these methods have limitations. Cultivation of mycoplasmas requires a complex medium, special equipment and technical skills (R.A.J. Nicholas et al., 2008; M.J. Calcutt et al., 2018; A.M. Andersson et al., 2019). Mycoplasmas require 7-10-day cultivation at a temperature of $37{ }^{\circ} \mathrm{C}$ and $5-10 \% \mathrm{CO}$. The colony has the "Fried-egg" appearance characteristic of most mycoplasmas (P.J. Quinn et al., 2011). By contrast, PCR provides a rapid and accurate diagnosis of the disease by detecting mycoplasmal DNA (A. M. Andersson et al., 2019). Furthermore, many other methods of diagnostics of bovine mycoplasma are used, such as MALDI-TOF MS (Matrix assisted laser desorption ionization time-of-light mass spectrometry), latex agglutination, immunochromatographic assays etc., however, each method has its advantages and disadvantages, which should be considered before application (M.J. Calcutt et al., 2018; B. Pardon et al., 2020).

Keywords: Mycoplasma bovis, Mycoplasma bovigenitalium, Mycoplasma dispar, cattle, pathogens, epidemiology.

\section{REF EREN C ES}

1. Bergey's manual ${ }^{\circledR}$ of systematic bacteriology. Volume 3: The Firmicutes. P. Vos, G. Garrity, D. Jones, N.R. Krieg, W. Ludwig, F.A. Rainey, K.H. Schleifer, W.B. Whitman (eds.). Springer Science \& Business Media, 2011 (doi: 10.1007/978-0-387-68489-5).

2. Nocard M., Roux M., Borrel M., Salimbeniet M., Dujardin-Beaumetz M. The microbe of pleuropneumonia. Reviews of Infectious Diseases, 1990, 12(2): 354-358 (doi: 10.1093/clinids/12.2.354).

3. Dupuy V., Manso-Silván L., Barbe V., Thebault P., Dordet-Frisoni E., Citti C., Poumarat F., 
Blanchard A., Breton M., Sirand-Pugnet P., Thiaucourt F. Evolutionary history of contagious bovine pleuropneumonia using next generation sequencing of Mycoplasma mycoides subsp. mycoides "small colony". PLoS ONE, 2012, 7(10): e46821 (doi: 10.1371/journal.pone.0046821).

4. Manso-Silván L., Dupuy V., Lysnyansky I., Ozdemir U., Thiaucourt F. Phylogeny and molecular typing of Mycoplasma agalactiae and Mycoplasma bovis by multilocus sequencing. Veterinary microbiology, 2012, 161(1-2): 104-112 (doi: 10.1016/j.vetmic.2012.07.015).

5. Mycoplasma protocols. R.J. Miles, R.A.J. Nicholas (eds.). Humana Press, 1998 (doi: 10.1385/0896035255).

6. Mycoplasma diseases of ruminants. R. Nicholas, R. Ayling, L. McAuliffe (eds.). Wallingford, CABI, 2008 (doi: 10.1079/9780851990125.0000).

7. Quinn P.J., Markey B.K., Leonard F.C., Hartigan P., Fanning S., Fitzpatrick E.S. Veterinary microbiology and microbial disease, 2nd Edition. Wiley-Blackwell, 2011.

8. Maunsell F.P., Woolums A.R., Francoz D., Rosenbusch R.F., Step D.L., Wilson D.J., Janzen E.D. Mycoplasma bovis infections in cattle. Journal of Veterinary Internal Medicine, 2011, 25(4): 772-783 (doi: 10.1111/j.1939-1676.2011.0750.x).

9. Pitcher D.G., Nicholas R.A.J. Mycoplasma host specificity: fact or fiction? The Veterinary Journal, 2005, 170(3): 300-306 (doi: 10.1016/J.TVJL.2004.08.011).

10. Radaelli E., Luini M., Loria G.R., Nicholas R.A.J., Scanziani E. Bacteriological, serological, pathological and immunohistochemical studies of Mycoplasma bovis respiratory infection in veal calves and adult cattle at slaughter. Research in Veterinary Science, 2008, 85(2): 282-290 (doi: 10.1016/J.RVSC.2007.11.012).

11. Caswell J.L., Archambault M. Mycoplasma bovis pneumonia in cattle. Animal Health Research Reviews, 2007, 8(2): 161-186 (doi: 10.1017/S1466252307001351).

12. Rodríguez F., Bryson D.G., Ball H.J., Forster F. Pathological and immunohistochemical studies of natural and experimental Mycoplasma bovis pneumonia in calves. Journal of Comparative Pathology, 1996, 115(2): 151-162 (doi: 10.1016/S0021-9975(96)80037-5).

13. Maunsell F.P., Donovan G.A. Mycoplasma bovis infections in young calves. Veterinary Clinics of North America: Food Animal Practice, 2009, 25(1): 139-177 (doi: 10.1016/J.CVFA.2008.10.011).

14. Nicholas R.A.J., Fox L.K., Lysnyansky I. Mycoplasma mastitis in cattle: To cull or not to cull. The Veterinary Journal, 2016, 216: 142-147 (doi: 10.1016/J.TVJL.2016.08.001).

15. Houlihan M.G., Veenstra B., Christian M.K., Nicholas R., Ayling R. Mastitis and arthritis in two dairy herds caused by Mycoplasma bovis. Veterinary Record, 2007, 160(4): 126-127 (doi: 10.1136/vr.160.4.126).

16. Wilson D.J., Skirpstunas R.T., Trujillo J.D., Cavender K.B., Bagley C.V., Harding R.L. Unusual history and initial clinical signs of Mycoplasma bovis mastitis and arthritis in first-lactation cows in a closed commercial dairy herd. Journal of the American Veterinary Medical Association, 2007, 230(10): 1519-1523 (doi: 10.2460/javma.230.10.1519).

17. Ross R.F. Mycoplasma - animal pathogens. In: Rapid diagnosis of mycoplasmas. Federation of European microbilogical societies symposium series, vol. 62. Springer, Boston, MA, 1993: 69-109 (doi: 10.1007/978-1-4615-2478-6_7).

18. Nicholas R.A.J., Ayling R.D. Mycoplasma bovis: disease, diagnosis, and control. Research in Veterinary Science, 2003, 74(2): 105-112 (doi: 10.1016/S0034-5288(02)00155-8).

19. Lysnyansky I., Brenner J., Bernstein M., Elad D., Blum S., Friedgut O., Rotenberg D., Alpert N., Benjamin A. Identification of Mycoplasma bovigenitalium and Mycoplasma canadense from outbreaks of granulopapular vulvovaginitis in dairy cattle in Israel. Veterinary Record, 2009, 165(11): 319-322 (doi: 10.1136/vr.165.11.319).

20. Parker A.M., Sheehy P.A., Hazelton M.S., Bosward K.L., House J.K. A review of mycoplasma diagnostics in cattle. Journal of Veterinary Internal Medicine, 2018, 32(3): 1241-1252 (doi: 10.1111/jvim.15135).

21. Ter Laak E.A., Noordergraaf J.H., Boomsluiter E. The nasal mycoplasmal flora of healthy calves and cows. Journal of Veterinary Medicine, Series B, 1992, 39(1-10): 610-616 (doi: 10.1111/j.14390450.1992.tb01212.x).

22. Ter Laak E.A., Noordergraaf J.H., Dieltjes R.P.J.W. Prevalence of mycoplasmas in the respiratory tracts of pneumonic calves. Journal of Veterinary Medicine, Series B, 1992, 39(1-10): 553-562 (doi: 10.1111/j.1439-0450.1992.tb01205.x).

23. Tegtmeier C., Uttenthal A., Friis N.F., Jensen N.E., Jensen H.E. Pathological and microbiological studies on pneumonic lungs from Danish calves. Journal of Veterinary Medicine, Series B, 1999, 46(10): 693-700 (doi: 10.1046/j.1439-0450.1999.00301.x).

24. Dabo S.M., Taylor J.D., Confer A.W. Pasteurella multocida and bovine respiratory disease. Animal Health Research Reviews, 2008, 8(2): 129-150 (doi: 10.1017/S1466252307001399).

25. Almeida R.A., Rosenbusch R.F. Capsulelike surface material of Mycoplasma dispar induced by in vitro growth in culture with bovine cells is antigenically related to similar structures expressed in vivo. Infection and Immunity, 1991, 59(9): 3119-3125 (doi: 10.1128/iai.59.9.3119-3125.1991).

26. Ayling R.D., Bashiruddin S.E., Nicholas R.A.J. Mycoplasma species and related organisms isolated from ruminants in Britain between 1990 and 2000. Veterinary Record, 2004, 155(14): 413-416 
(doi: 10.1136/VR.155.14.413).

27. Taylor G. Immunity to mycoplasma infections of the respiratory tract: a review. Journal of the Royal Society of Medicine, 1979, 72(7): 520-526 (doi: 10.1177/014107687907200711).

28. Gourlay R.N., Howard C.J., Thomas L.H., Wyld S.G. Pathogenicity of some Mycoplasma and Acholeplasma species in the lungs of gnotobiotic calves. Research in Veterinary Science, 1979, 27(2): 233-237 (doi: 10.1016/S0034-5288(18)32836-4).

29. Bürki S., Frey J., Pilo P. Virulence, persistence and dissemination of Mycoplasma bovis. Veterinary Microbiology, 2015, 179(1-2): 15-22 (doi: 10.1016/j.vetmic.2015.02.024).

30. O'Brien D., Scudamore J., Charlier J., Delavergne M. DISCONTOOLS: a database to identify research gaps on vaccines, pharmaceuticals and diagnostics for the control of infectious diseases of animals. BMC Veterinary Research, 2016, 13: 1 (doi: 10.1186/s12917-016-0931-1).

31. Abed Alkhussen M., Nesterov A.A., Kirpichenko V.V., Yatsentyuk S.P., Sprygin A.V., B'yadovskaya O.P., Kononov A.V. Veterinariya segodnya, 2020, 2: 102-108 (doi: 10.29326/2304196X-2020-2-33-102-108) (in Russ.).

32. Langford E.V. Isolation of Mycoplasma bovigenitalium from an aborted equine foetus. Veterinary Record, 1974, 94(23): 528 (doi: 10.1136/vr.94.23.528).

33. Macêdo A.A.M., Oliveira J.M.B., Silva B.P., Borges J.M., Soares L.B.F., Silva G.M., Santos S.B., Mota R.A., Pinheiro-Júnior J.W. Occurrence of Mycoplasma bovigenitalium and Ureaplasma diversum in dairy cattle from to Pernambuco state, Brazil. Arquivo Brasileiro de Medicina Veterinária e Zootecnia, 2018, 70(6): 1798-1806 (doi: 10.1590/1678-4162-10132).

34. Ose E.E., Muenster O.A. Isolation of Mycoplasma dispar from cattle in the United States. Veterinary Record, 1975, 97: 11 (doi: 10.1136/VR.97.5.97).

35. Tortorelli G., Carrillo Gaeta N., Mendonзa Ribeiro B.L., Miranda Marques L., Timenetsky J., Gregory L. Evaluation of Mollicutes microorganisms in respiratory disease of cattle and their relationship to clinical signs. Journal of Veterinary Internal Medicine, 2017, 31(4): 1215-1220 (doi: 10.1111/jvim.14721).

36. Gourlay R.N., Leach R.H. A new mycoplasma species isolated from pneumonic lungs of calves (Mycoplasma dispar sp. nov.). Journal of Medical Microbiology, 1970, 3(1): 111-123 (doi: 10.1099/00222615-3-1-111).

37. França Dias de Oliveira B.A., Carrillo Gaeta N., Mendonça Ribeiro B.L., Reyes Alemán M.A., Miranda Marques L., Timenetsky J., Melville P.A., Avansi Marques J., Marvulle V., Gregory L. Determination of bacterial aetiologic factor on tracheobronchial lavage in relation to clinical signs of bovine respiratory disease. Journal of Medical Microbiology, 2016, 65(10): 1137-1142 (doi: 10.1099/jmm.0.000345).

38. Bottinelli M., Passamonti F., Rampacci E., Stefanetti V., Pochiero L., Coletti M., Rueca F., Hyatt D.R., Schnee C. DNA microarray assay and real-time PCR as useful tools for studying the respiratory tract Mycoplasma populations in young dairy calves. Journal of Medical Microbiology, 2017, 66(9): 1342-1349 (doi: 10.1099/jmm.0.000571).

39. Veterinary microbiology, 3rd Edition. D.S. McVey, M. Kennedy, M.M. Chengappa (eds.). WileyBlackwell, 2013.

40. Khan L.A., Miles R.J., Nicholas R.A.J. Hydrogen peroxide production by Mycoplasma bovis and Mycoplasma agalactiae and effect of in vitro passage on a Mycoplasma bovis strain producing high levels of $\mathrm{H}_{2} \mathrm{O}_{2}$. Veterinary Research Communications, 2005, 29(3): 181-188 (doi: 10.1023/b:verc.0000047506.04096.06).

41. Zhao G., Zhang H., Chen X., Zhu X., Guo Y., He C., Anwar Khan F., Chen Y., Hu C., Chen H., Guo A. Mycoplasma bovis NADH oxidase functions as both a NADH oxidizing and $\mathrm{O}_{2}$ reducing enzyme and an adhesin. Scientific Reports, 2017, 7(1): 44 (doi: 10.1038/s41598-01700121-y).

42. Cole B.C., Ward J.R., Martin C.H. Hemolysin and peroxide activity of Mycoplasma species. Journal of Bacteriology, 1968, 95(6): 2022-2030 (doi: 10.1128/jb.95.6.2022-2030.1968).

43. Nicholas R.A., Lin Y.C., Sachse K., Hotzel H., Parham K., McAuliffe L., Miles R. J., Kelly D.P., Wood A.P. Proposal that the strains of the Mycoplasma ovine/caprine serogroup 11 be reclassified as Mycoplasma bovigenitalium. International Journal of Systematic and Evolutionary Microbiology, 2008, 58(1): 308-312 (doi: 10.1099/ijs.0.65553-0).

44. Nicholas R.A., Khan L.A., Houshaymi B., Miles R.J., Ayling R.D., Hotzel H., Sachse K. Close genetic and phenotypic relatedness between Mycoplasma ovine/caprine serogroup 11 and Mycoplasma bovigenitalium. Systematic and Applied Microbiology, 2002, 25(3): 396-402 (doi: 10.1078/0723-2020-00121).

45. Uphoff C.C., Drexler H.G. Detection of mycoplasma contamination in cell cultures. Current Protocols in Molecular Biology, 2014, 106(1): 24-28 (doi: 10.1002/0471142727.mb2804s106).

46. Klein U., de Jong A., Youala M., El Garch F., Stevenin C., Moyaert H., Rose M., Catania S., Gyuranecz M., Pridmore A., Ayling R.D. New antimicrobial susceptibility data from monitoring of Mycoplasma bovis isolated in Europe. Veterinary Microbiology, 2019, 238: 108432 (doi: 10.1016/j.vetmic.2019.108432).

47. Chernova O.A., Medvedeva E.S., Muzykantov A.A., Baranova N.B., Chernov V.M. Acta Naturae, 
2016, 8(2): 27-38 (doi: 10.32607/20758251-2016-8-2-24-34) (in Russ.).

48. Maes D., Boyen F., Haesebrouck F., Gautier-Bouchardon A.V. Antimicrobial treatment of Mycoplasma hyopneumoniae infections. The Veterinary Journal, 2020, 259-260: 105474 (doi: 10.1016/j.tvjl.2020.105474).

49. Gautier-Bouchardon A.V. Antimicrobial resistance in Mycoplasma spp. In: Antimicrobial resistance in bacteria from livestock and companion animals. S. Schwarz, L.M. Cavaco, J. Shen (eds). American Society of Microbiology Press, 2018: 425-446 (doi: 10.1128/9781555819804.ch20).

50. Lysnyansky I., Ayling R.D. Mycoplasma bovis: mechanisms of resistance and trends in antimicrobial susceptibility. Frontiers in Microbiology, 2016, 7: 595 (doi: 10.3389/fmicb.2016.00595).

51. Reinhardt A.K., Kempf I., Kobisch M., Gautier-Bouchardon A.V. Fluoroquinolone resistance in Mycoplasma gallisepticum: DNA gyrase as primary target of enrofloxacin and impact of mutations in topoisomerases on resistance level. Journal of Antimicrobial Chemotherapy, 2002, 50(4): 589592 (doi: 10.1093/jac/dkf158).

52. Amram E., Mikula I., Schnee C., Ayling R.D., Nicholas R.A., Rosales R.S., Harrus S., Lysnyansky I. 16S rRNA gene mutations associated with decreased susceptibility to tetracycline in Mycoplasma bovis. Antimicrobial Agents and Chemotherapy, 2015, 59(2): 796-802 (doi: 10.1128/AAC.03876-14).

53. Kumar A., Verma A.K., Rahal A. Mycoplasma bovis, a multi disease producing pathogen: an overview. Asian Journal of Animal and Veterinary Advances, 2011, 6(6): 537-546 (doi: 10.3923/ajava.2011.537.546).

54. Pfützner H. Tenazität von Mycoplasma bovis. Zentralblatt für Bakteriologie, Mikrobiologie und Hygiene. Series A: Medical Microbiology, Infectious Diseases, Virology, Parasitology, 1984, 258(1): 38-41 (doi: 10.1016/S0176-6724(84)80006-1).

55. Wilson D.J., Justice-Allen A., Goodell G., Baldwin T.J., Skirpstunas R.T., Cavender K.B. Risk of Mycoplasma bovis transmission from contaminated sand bedding to naive dairy calves. Journal of Dairy Science, 2011, 94(3): 1318-1324 (doi: 10.3168/JDS.2010-3692).

56. Justice-Allen A., Trujillo J., Corbett R., Harding R., Goodell G., Wilson D. Survival and replication of Mycoplasma species in recycled bedding sand and association with mastitis on dairy farms in Utah. Journal of Dairy Science, 2010, 93(1): 192-202 (doi: 10.3168/JDS.2009-2474).

57. Aebi M., van den Borne B., Raemy A., Steiner A., Pilo P., Bodmer M. Mycoplasma bovis infections in Swiss dairy cattle: a clinical investigation. Acta Veterinaria Scandinavica, 2015, 57(1): 10 (doi: 10.1186/s13028-015-0099-x).

58. Amram E., Freed M., Khateb N., Mikula I., Blum S., Spergser J., Sharir B., Ozeri R., Harrus S., Lysnyansky I. Multiple locus variable number tandem repeat analysis of Mycoplasma bovis isolated from local and imported cattle. The Veterinary Journal, 2013, 197(2): 286-290 (doi: 10.1016/J.TVJL.2013.03.023).

59. Arede M., Nielsen P.K., Ahmed S.S.U., Halasa T., Nielsen L.R., Toft N. A space-time analysis of Mycoplasma bovis: bulk tank milk antibody screening results from all Danish dairy herds in 2013-2014. Acta Veterinaria Scandinavica, 2016, 58(1): 16 (doi: 10.1186/s13028-016-0198-3).

60. Visser I.J., ter Laak E.A., Jansen H.B. Failure of antibiotics gentamycin, tylosin, lincomycin and spectinomycin to eliminate Mycoplasma bovis in artificially infected frozen bovine semen. Theriogenology, 1999, 51(4): 689-697 (doi: 10.1016/s0093-691x(99)00018-7).

61. Bielanski A., Eaglesome M.D., Ruhnke H.L., Hare W.C.D. Isolation of Mycoplasma bovis from intact and microinjected preimplantation bovine embryos washed or treated with trypsin or antibiotics. Journal of in Vitro Fertilization and Embryo Transfer, 1989, 6(4): 236-241 (doi: 10.1007/BF01132872).

62. Kozlova A.D., Gorbacheva N.S., Khaerova R.F., Krasnikova M.S., Lazareva E.A., Yatsentyuk S.P. Differentiation of Mycoplasma bovis, Mycoplasma bovigenitalium, Mycoplasma californicum and identification of ureaplasma diversum by real-time PCR. Agricucltural Biology [Sel'skokhozyaistvennaya biologiya], 2019, 54(2): 378-385 (doi: 10.15389/agrobiology.2019.2.378eng).

63. Biddle M.K., Fox L.K., Hancock D.D. Patterns of mycoplasma shedding in the milk of dairy cows with intramammary mycoplasma infection. Journal of the American Veterinary Medical Association, 2003, 223(8): 1163-1166 (doi: 10.2460/javma.2003.223.1163).

64. Punyapornwithaya V., Fox L.K., Hancock D.D., Gay J.M., Alldredge J.R. Association between an outbreak strain causing mycoplasma bovis mastitis and its asymptomatic carriage in the herd: a case study from Idaho, USA. Preventive Veterinary Medicine, 2010, 93(1): 66-70 (doi: 10.1016/j.prevetmed.2009.08.008).

65. Woldehiwet Z., Mamache B., Rowan T.G. Effects of age, environmental temperature and relative humidity on the colonization of the nose and trachea of calves by Mycoplasma spp. British Veterinary Journal, 1990, 146(5): 419-424 (doi: 10.1016/0007-1935(90)90030-7).

66. Punyapornwithaya V., Fox L.K., Hancock D.D., Gay J.M., Wenz J.R., Alldredge J.R. Incidence and transmission of Mycoplasma bovis mastitis in Holstein dairy cows in a hospital pen: A case study. Preventive Veterinary Medicine, 2011, 98(1): 74-78 (doi: 10.1016/J.PREVETMED.2010.10.015). 
67. Pfützner H., Sachse K. Mycoplasma bovis as an agent of mastitis, pneumonia, arthritis and genital disorders in cattle. Revue Scientifique et Technique-Office International des Epizooties, 1996, 15(4): 1477-1494 (doi: 10.20506/rst.15.4.987).

68. Calcutt M.J., Lysnyansky I., Sachse K., Fox L.K., Nicholas R.A.J., Ayling R.D. Gap analysis of Mycoplasma bovis disease, diagnosis and control: An aid to identify future development requirements. Transboundary and Emerging Diseases, 2018, 65(S1): 91-109 (doi: 10.1111/tbed.12860).

69. Razin S., Jacobs E. Mycoplasma adhesion. Journal of General Microbiology, 1992, 138(3): 407422 (doi: 10.1099/00221287-138-3-407).

70. Sachse K., Grajetzki C., Rosengarten R., Hänel I., Heller M., Pfützner H. Mechanisms and factors involved in Mycoplasma bovis adhesion to host cells. Zentralblatt für Bakteriol, 1996, 284(1): 80-92 (doi: 10.1016/S0934-8840(96)80157-5).

71. Song Z., Li Y., Liu Y., Xin J., Zou X., Sun W. $\alpha$-Enolase, an adhesion-related factor of Mycoplasma bovis. PLoS ONE, 2012, 7(6): e38836 (doi: 10.1371/journal.pone.0038836).

72. Sachse K., Helbig J.H., Lysnyansky I., Grajetzki C., Müller W., Jacobs E., Yogev D. Epitope mapping of immunogenic and adhesive structures in repetitive domains of Mycoplasma bovis variable surface lipoproteins. Infection and Immunity, 2000, 68(2): 680-687 (doi: 10.1128/iai.68.2.680-687.2000).

73. Zou X., Li Y., Wang Y., Zhou Y., Liu Y., Xin J. Molecular cloning and characterization of a surface-localized adhesion protein in Mycoplasma bovis Hubei-1 strain. PLoS ONE, 2013, 8(7): e69644 (doi: 10.1371/journal.pone.0069644).

74. McAuliffe L., Ellis R.J., Miles K., Ayling R.D., Nicholas R.A.J. Biofilm formation by mycoplasma species and its role in environmental persistence and survival. Microbiology, 2006, 152(4): 913-922 (doi: 10.1099/mic.0.28604-0).

75. Shaw B.M., Simmons W.L., Dybvig K. The Vsa shield of Mycoplasma pulmonis is antiphagocytic. Infection and Immunity, 2012, 80(2): $704-709$ (doi: 10.1128/IAI.06009-11).

76. Citti C., Kim M.F., Wise K.S. Elongated versions of Vlp surface lipoproteins protect Mycoplasma hyorhinis escape variants from growth-inhibiting host antibodies. Infection and Immunity, 1997, 65(5): 1773-1785 (doi: 10.1128/iai.65.5.1773-1785.1997).

77. Guo Y., Zhu H., Wang J., Huang J., Khan F. A., Zhang J., Guo A., Chen X. TrmFO, a fibronectin-binding adhesin of Mycoplasma bovis. International journal of molecular sciences., 2017, 18(8): 1732 (doi: 10.3390/ijms18081732).

78. van der Merwe J., Prysliak T., Perez-Casal J. Invasion of bovine peripheral blood mononuclear cells and erythrocytes by Mycoplasma bovis. Infection and Immunity, 2010, 78(11): 4570-4578 (doi: 10.1128/IAI.00707-10).

79. Maeda T., Shibahara T., Kimura K., Wada Y., Sato K., Imada Y., Ishikawa Y., Kadota K. Mycoplasma bovis-associated suppurative otitis media and pneumonia in bull calves. Journal of comparative pathology, 2003, 129(2-3): 100-110 (doi: 10.1016/S0021-9975(03)00009-4).

80. Suleman M., Prysliak T., Clarke K., Burrage P., Windeyer C., Perez-Casal J. Mycoplasma bovis isolates recovered from cattle and bison (Bison bison) show differential in vitro effects on PBMC proliferation, alveolar macrophage apoptosis and invasion of epithelial and immune cells. Veterinary Microbiology, 2016, 186: 28-36 (doi: 10.1016/J.VETMIC.2016.02.016).

81. Simmons W.L., Daubenspeck J.M., Osborne J.D., Balish M.F., Waites K.B., Dybvig K. Type 1 and type 2 strains of Mycoplasma pneumoniae form different biofilms. Microbiology, 2013, 159(Pt 4): 737-747 (doi: 10.1099/mic.0.064782-0).

82. Wang Y., Yi L., Zhang F., Qiu X., Tan L., Yu S., Cheng X., Ding C. Identification of genes involved in Mycoplasma gallisepticum biofilm formation using mini-Tn4001-SGM transposon mutagenesis. Veterinary Microbiology, 2017, 198: 17-22 (doi: 10.1016/J.VETMIC.2016.11.021).

83. Gomes F., Saavedra M.J., Henriques M. Bovine mastitis disease/pathogenicity: evidence of the potential role of microbial biofilms. Pathogens and Disease, 2016, 74(3): ftw006 (doi: 10.1093/femspd/ftw006).

84. Melchior M.B., Vaarkamp H., Fink-Gremmels J. Biofilms: a role in recurrent mastitis infections? The Veterinary Journal, 2006, 171(3): 398-407 (doi: 10.1016/J.TVJL.2005.01.006).

85. McAuliffe L., Ayling R.D., Ellis R.J., Nicholas R.A.J. Biofilm-grown Mycoplasma mycoides subsp. mycoides SC exhibit both phenotypic and genotypic variation compared with planktonic cells. Veterinary Microbiology, 2008, 129(3-4): 315-324 (doi: 10.1016/J.VETMIC.2007.11.024).

86. Whitman R., Harwood V.J., Edge T.A., Nevers M., Byappanahalli M., Vijayavel K., Brandão J., Sadowsky M. J., Alm E.W., Crowe A., Ferguson D., Ge Z., Halliday E., Kinzelman J., Kleinheinz G., Przybyla-Kelly K., Staley C., Staley Z., Solo-Gabriele H.M. Microbes in beach sands: integrating environment, ecology and public health. Reviews in Environmental Science and Bio/Technology, 2014, 13(3): 329-368 (doi: 10.1007/s11157-014-9340-8).

87. Rasheed M.A., Qi J., Zhu X., Chenfei H., Menghwar H., Khan F.A., Zhao G., Zubair M., $\mathrm{Hu}$ C., Chen Y., Chen H., Guo A. Comparative genomics of Mycoplasma bovis strains reveals that decreased virulence with increasing passages might correlate with potential virulencerelated factors. Frontiers in Cellular and Infection Microbiology, 2017, 7: 177 (doi: 
10.3389/fcimb.2017.00177).

88. Andersson A., Aspán A., Wisselink H.J., Smid B., Ridley A.M., Pelkonen S., Autio T., Lauritsen K.T., Kensø J., Gaurivaud P., Tardy F. A European inter-laboratory trial to evaluate the performance of three serological methods for diagnosis of Mycoplasma bovis infection in cattle using latent class analysis. BMC Veterinary Research, 2019, 15(1): 369 (doi: 10.1186/s12917-0192117-0).

89. Clothier K.A., Jordan D.M., Thompson C.J., Kinyon J.M., Frana T.S., Strait E.L. Mycoplasma Bovis real-time polymerase chain reaction assay validation and diagnostic performance. Journal of Veterinary Diagnostic Investigation, 2010, 22(6): 956-960 (doi: 10.1177/104063871002200618).

90. Bokma J., Van Driessche L., Deprez P., Haesebrouck F., Vahl M., Weesendorp E., Deurenberg R.H., Pardon B., Boyen F. Rapid identification of Mycoplasma bovis strains from bovine bronchoalveolar lavage fluid with matrix-assisted laser desorption ionization-time of flight mass spectrometry after enrichment procedure. Journal of Clinical Microbiology, 2020, 58(6): e00004-20 (doi: 10.1128/JCM.00004-20).

91. Pardon B., Buczinski S. Bovine respiratory disease diagnosis: what progress has been made in infectious diagnosis? Veterinary Clinics: Food Animal Practice, 2020, 36(2): 425-444 (doi: 10.1016/j.cvfa.2020.03.005).

92. Wisselink H.J., Smid B., Plater J., Ridley A., Andersson A.M., Aspán A., Pohjanvirta T., Vähänikkilä N., Larsen H., Høgberg J., Colin A., Tardy F. A European interlaboratory trial to evaluate the performance of different PCR methods for Mycoplasma bovis diagnosis. BMC Veterinary Research, 2019, 15(1): 86 (doi: 10.1186/s12917-019-1819-7).

93. Pardon B., Callens J., Maris J., Allais L., Van Praet W., Deprez P., Ribbens S. Pathogen-specific risk factors in acute outbreaks of respiratory disease in calves. Journal of Dairy Science, 2020, 103(3): 2556-2566 (doi: 10.3168/jds.2019-17486).

94. O’Neill R., Mooney J., Connaghan E., Furphy C., Graham D.A. Patterns of detection of respiratory viruses in nasal swabs from calves in Ireland: a retrospective study. Veterinary Record, 2014, 175(14): 351 (doi: 10.1136/vr.102574).

95. Angen O., Thomsen J., Larsen L.E., Larsen J., Kokotovic B., Heegaard P.M., Enemark J.M. Respiratory disease in calves: microbiological investigations on trans-tracheally aspirated bronchoalveolar fluid and acute phase protein response. Veterinary Microbiology, 2009, 137(1-2): 165-171 (doi: 10.1016/j.vetmic.2008.12.024).

96. Sachse K., Salam H.S.H., Diller R., Schubert E., Hoffmann B., Hotzel H. Use of a novel realtime PCR technique to monitor and quantitate Mycoplasma bovis infection in cattle herds with mastitis and respiratory disease. The Veterinary Journal, 2010, 186(3): 299-303 (doi: 10.1016/J.TVJL.2009.10.008).

97. Rossetti B.C., Frey J., Pilo P. Direct detection of Mycoplasma bovis in milk and tissue samples by real-time PCR. Molecular and Cellular Probes, 2010, 24(5): 321-323 (doi: 10.1016/J.MCP.2010.05.001).

98. Cornelissen J.B., de Bree F.M., van der Wal F.J., Kooi E.A., Koene M.G., Bossers A., Smid B., Antonis A.F., Wisselink H.J. Mycoplasma detection by triplex real-time PCR in bronchoalveolar lavage fluid from bovine respiratory disease complex cases. BMC Veterinary Research, 2017, 13(1): 97 (doi: 10.1186/s12917-017-1023-6).

99. Parker A.M., House J.K., Hazelton M.S., Bosward K.L., Sheehy P.A. Comparison of culture and a multiplex probe PCR for identifying Mycoplasma species in bovine milk, semen and swab samples. G.F. Browning (ed.). PLoS ONE, 2017, 12(3): e0173422 (doi: 10.1371/journal.pone.0173422).

100. McAuliffe L., Ellis R.J., Lawes J.R., Ayling R.D., Nicholas R.A. 16S rDNA PCR and denaturing gradient gel electrophoresis; a single generic test for detecting and differentiating Mycoplasma species. Journal of Medical Microbiology, 2005, 54(8): 731-739 (doi: 10.1099/jmm.0.46058-0).

101. Schnee C., Schulsse S., Hotzel H., Ayling R.D., Nicholas R.A., Schubert E., Heller M., Ehricht R., Sachse K.A. Novel rapid dna microarray assay enables identification of 37 mycoplasma species and highlights multiple mycoplasma infections. PLoS ONE, 2012, 7(3): e33237 (doi: 10.1371/journal.pone.0033237).

102. Spergser J., Hess C., Loncaric I., Ramhrez A.S. Matrix-assisted laser desorption ionization-time of flight mass spectrometry is a superior diagnostic tool for the identification and differentiation of mycoplasmas isolated from animals. Journal of Clinical Microbiology, 2019, 57(9): e00316-19. (doi: 10.1128/JCM.00316-19).

103. Van Driessche L., Bokma J., Deprez P., Haesebrouck F., Boyen F., Pardon B. Rapid identification of respiratory bacterial pathogens from bronchoalveolar lavage fluid in cattle by MALDI-TOF MS. Scientific Reports, 2019, 9(1): 1-8 (doi: 10.1038/s41598-019-54599-9).

104. Edwards D.J., Holt K.E. Beginner's guide to comparative bacterial genome analysis using nextgeneration sequence data. Microbial Informatics and Experimentation, 2013, 3(1): 2 (doi: 10.1186/2042-5783-3-2).

105. Chen S., Hao H., Zhao P., Gao P., He Y., Ji W., Wang Z., Lu Z., Liu Y., Chu Y. Complete genome sequence of Mycoplasma bovis strain 08M. Genome Announcements, 2017, 5(19): e00324- 
17 (doi: 10.1128/genomeA.00324-17).

106. Qi J., Guo A., Cui P., Chen Y., Mustafa R., Ba X., Hu C., Bai Z., Chen X., Shi L., Chen H. Comparative geno-plasticity analysis of Mycoplasma bovis HB0801 (Chinese isolate). PLoS ONE, 2012, 7(5): e38239 (doi: 10.1371/journal.pone.0038239).

107. Sun P., Luo H., Zhang X., Xu J., Guo Y., He S. Whole-genome sequence of Mycoplasma bovis strain Ningxia-1. Genome Announcements, 2018, 6(4): e01367-17 (doi: 10.1128/genomeA.0136717).

108. Calcutt M.J., Foecking M.F., Fox L.K. Complete genome sequence of the bovine mastitis pathogen Mycoplasma californicum strain ST-6T (ATCC 33461T). Genome Announcements, 2014, 2(4): e00648-14 (doi: 10.1128/genomeA.00648-14).

109. Hata E., Murakami K. Complete genome sequence of Mycoplasma californicum strain HAZ160_1 from bovine mastitic milk in Japan. Genome Announcements, 2014, 2(4): e00684-14 (doi: 10.1128/genomeA.00684-14).

110. Hata E. Complete genome sequence of Mycoplasma arginini strain HAZ 145_1 from bovine mastitic milk in Japan. Genome Announcements, 2015, 3(2): e00265-15 (doi: 10.1128/genomeA.00265-15).

111. Hata E., Nagai K., Murakami K. Complete genome sequence of Mycoplasma bovigenitalium strain HAZ 596 from a bovine vagina in Japan. Genome Announcements, 2017, 5(6): e01554-16 (doi: 10.1128/genomeA.01554-16).

112. Hata E. Complete genome sequence of Mycoplasma canadense strain HAZ 360_1 from bovine mastitic milk in Japan. Genome Announcements, 2014, 2(5): e00984-14 (doi: 10.1128/genomeA.00984-14).

113. Calcutt M.J., Foecking M.F. Complete genome sequence of Mycoplasma bovoculi strain M165/69T (ATCC 29104). Genome Announcements, 2014, 2(1): e00115-14 (doi: 10.1128/genomeA.00115-14).

114. Wise K.S., Calcutt M.J., Foecking M.F., Madupu R., DeBoy R.T., Rцske K., Hvinden M.L., Martin T.R., Durkin A.S., Glass J.I., Methй B.A. Complete genome sequences of Mycoplasma leachii strain PG50T and the pathogenic Mycoplasma mycoides subsp. mycoides small colony biotype strain Gladysdale. Journal of Bacteriology, 2012, 194(16): 4448-4449 (doi: 10.1128/JB.00761-12).

115. Ashraf A., Imran M., Yaqub T., Tayyab M., Shehzad W., Mingala C.N., Chang Y.F. Development and validation of a loop-mediated isothermal amplification assay for the detection of Mycoplasma bovis in mastitic milk. Folia Microbiologica, 2018, 63(3): 373-380 (doi: 10.1007/s12223-017-0576-x).

116. Higa Y., Uemura R., Yamazaki W., Goto S., Goto Y., Sueyoshi M. An improved loop-mediated isothermal amplification assay for the detection of Mycoplasma bovis. Journal of Veterinary Medical Science, 2016, 78(8): 1343-1346 (doi: 10.1292/jvms.15-0459). 